\title{
Behavioural validation of a parent-report measure of child food fussiness
}

\section{Article}

\section{Accepted Version}

Creative Commons: Attribution-Noncommercial-No Derivative Works 4.0

Rendall, S., Dodd, H. and Harvey, K. (2020) Behavioural validation of a parent-report measure of child food fussiness. Appetite, 154. 104796. ISSN 0195-6663 doi: https://doi.org/10.1016/j.appet.2020.104796 Available at https://centaur.reading.ac.uk/91633/

It is advisable to refer to the publisher's version if you intend to cite from the work. See Guidance on citing.

To link to this article DOI: http://dx.doi.org/10.1016/j.appet.2020.104796

Publisher: Elsevier

All outputs in CentAUR are protected by Intellectual Property Rights law, including copyright law. Copyright and IPR is retained by the creators or other copyright holders. Terms and conditions for use of this material are defined in the End User Agreement.

\section{www.reading.ac.uk/centaur}

\section{CentAUR}

Central Archive at the University of Reading

Reading's research outputs online 
1

2

3

4

5

6

7

8

9

10

11

12

13

14

15

16

17

18

19

20

21

22

23

24

25

Running Title: Validation of the CEBQ FF

Behavioural validation of a parent-report measure of child food fussiness

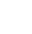

Stella Rendall ${ }^{1}$, Helen Dodd $^{2}$, Kate Harvey $^{3}$

1,2,3 School of Psychology \& Clinical Language Sciences, University of Reading, Reading, RG6 6AL, UK

2 All correspondence should be addressed to: ${ }^{3}$ Email: k.n.harvey@ reading.ac.uk (Kate

3 Harvey)

4 Not for publication: Tel +44 (0)118 3787524

School of Psychology \& Clinical Language Science, University of Reading, Reading, RG6 6AL, UK. 
26 Abstract

27 Food fussiness is the rejection of familiar and novel foods leading to consumption that is insufficient and/or inadequately varied. Its importance to children's nutrition and the development of food preferences means it has been the focus of extensive research. To measure food fussiness, research has predominantly relied on parent-report, though parents' reporting of their child's eating behaviour can be reliable, responses may also be subject to bias. Utilising data from video-recordings of sixty-seven mother-child dyads during a meal in the home environment, this study aimed to validate the most widely used parent-report questionnaire measuring food fussiness against independent observations of children's eating behaviour and, in so doing, determine its accuracy. Maternal reported food fussiness, assessed using the Food Fussiness subscale of the Children's Eating Behaviour Questionnaire (CEBQ; Wardle, Guthrie, Sanderson, \& Rapoport, 2001) was compared to children's observed food rejection and acceptance behaviours. Bootstrapped Pearson's correlations revealed that maternal reports of food fussiness were significantly positively related to food rejection behaviours and significantly negatively related to food acceptance behaviours. Maternal reports of food fussiness were also found to be significantly negatively related to the proportion of familiar/appealing of familiar foods consumed by the child. There was no significant association between maternal reported food fussiness and the proportion of familiar/unappealing, unfamiliar/appealing and unfamiliar/unappealing foods consumed by the child or the meal duration. These findings support the CEBQ FF as a valid measure of food fussiness. 


\section{INTRODUCTION}

Food fussiness, characterised by the rejection of familiar and novel foods resulting in a diet that is insufficient and/or inadequately varied (Dovey, Staples, Gibson, \& Halford, 2008) is a common childhood problem, with a prevalence of $50 \%$ in children's second year (Carruth, Ziegler, Gordon, \& Barr, 2004). As children this age would be unreliable reporters of their eating behaviour, most research in this field has used parent-report to assess food fussiness (e.g., Carruth et al., 1998; Galloway, Fiorito, Lee, \& Birch, 2005; Hafstad, Abebe, Torgersen, \& von Soest, 2013; Haycraft, Farrow, Meyer, Powell, \& Blissett, 2011). The cost effectiveness and ease with which parent-report questionnaires can be administered on a large scale makes them practical (Carnell \& Wardle, 2007), however, parent-report can be subject to biases and inconsistencies (e.g., Boquin, Moskowitz, Donovan, \& Lee, 2014; Goh \& Jacob, 2012). Although evidence suggests that parents can be reliable informants of their children's eating behaviour (e.g., Cooper, Whelan, Woolgar, Morrell, \& Murray, 2004), research validating parent-report against independent observations of children's eating behaviour is crucial to comprehensively evaluate its reliability.

The Food Fussiness (FF) subscale of the CEBQ (Wardle et al., 2001) is widely used to assess food fussiness in young children (Farrow \& Coulthard, 2012; Hendy, Williams, Riegel, \& Paul, 2010; Jansen et al., 2012; Tharner et al., 2015; van der Horst, 2012). It has good internal validity (e.g., Wardle et al, 2001) and responses on the FF subscale are related to other parent-report measures of food fussiness. For example, the CEBQ was found to be accurate at discriminating between fussy and non-fussy eaters who were categorised using a structured parent interview (Steinsbekk, Hamre Sveen, Fildes, Llewellyn, \& Wichstrøm, 2017). Similarly, Rogers, Ramsey and Blissett (2018) found the CEBQ FF subscale to have good criterion validity with the Montreal Children's Hospital Feeding Scale (MCHFS; 
Ramsay, Martel, Porporino \& Zygmuntowicz, 2011), a brief 14 item parent-report measure of children's feeding problems.

A handful of studies have aimed to establish the reliability of the CEBQ FF by comparing it to observations of children's eating. In one, Fernandez et al. (2018) observed children's responses to two familiar and two unfamiliar vegetables in a laboratory settting. They found that maternal responses on the CEBQ FF scale were associated with observed food refusal behaviours characterised by children's consumption of fewer grams of food, fewer bites, more negative utterances about the food, less compliance with maternal encouragements to eat and longer observed latency to the first bite. In another, Werthmann et al., (2015) offered children variants of a well-known yoghurt whilst they were in day care, with texture, taste and colour manipulated. Food acceptance was measured via the amount consumed. In contrast to Fernandez et al's (2018) laboratory study, Werthmann and colleagues found that parental reports of food fussiness on the CEBQ FF scale were not related to observations of children's yoghurt acceptance. Similarly, Surette, Ward, Morin, Vatanparast, \& Bélanger, (2017) found that observed food fussiness, established from children's plate waste after a meal in a day care setting, did not correspond to parental reported CEBQ FF scores. Thus, there is some inconsistency regarding how well the CEBQ FF scale aligns with observed fussy eating. It should be noted that there is considerable disparity regarding how food fussiness was determined in the observations across these studies which could account for some of this inconsistency. For example, Fernandez et al. (2018) determined food fussiness by fewer grams of food consumed as well as the child's hedonic rating of food while plate waste analysis was used to establish a proxy measure of food fussiness in Surette et al's (2017) study.

Inconsistent findings could also arise because of study limitations. While the laboratory setting used by Fernandez et al. (2018) has the advantage of ensuring control of extraneous 
variables, the artificial environment may also have elicited behaviours from children that were not typical for them. Arguably, while the day-care centres used by Werthmann et al. (2015) and Surette et al. (2017) can be considered more naturalistic, the setting may still introduce bias. Day-care settings have been found to produce elevated stress levels in young children, as peer groups are a demanding context and have been shown to produce high emotional arousal (Vermeer \& van IJzendoorn, 2006). It is therefore plausible that the daycare environment, like the laboratory setting, may also influence children's eating behaviour in unanticipated ways.

The majority of young children are most familiar with eating meals at home, and so it is in this naturalistic environment that researchers are most likely to be able to observe children's food fussiness. Recently, Fries, Martin, \& van der Horst, (2017) validated parental report of food fussiness by comparing CEBQ FF scores with video-recorded observations of children's food refusal in a home environment. Fries et al. found no differences in overall food refusal between fussy and non-fussy groups as defined by the CEBQ FF, however they acknowledge a key weakness in the design of their study. Specifically, parents were not guided in which food they offered their child and it is plausible that parents of fussy eaters may have chosen to offer foods they judged their child more likely to accept, thus explaining why fussy eaters displayed few food refusal behaviours during the observed mealtime. This interpretation was supported by their finding from questionnaire items indicating that parents who tended to "give up" after their child had refused disliked foods and provide them with an alternative meal consisting of their favourite foods had children who made more refusals when presented with a novel food.

The current study aimed to establish the validity of the CEBQ FF subscale using observational data while aiming to address the weaknesses of existing studies. Specifically, the focus was on ensuring the study was as naturalistic as possible, by observing children 
eating a meal at home in the presence of their parent. The food offered was manipulated to comprise familiar and unfamiliar foods as well as foods likely to be broadly appealing and unappealing to children. Foods differ in their level of appeal to young children according to sensory characteristics such as texture, colour and taste. For example, foods with slimy and mushy textures as well as green foods have been found to be unappealing to young children while brightly coloured foods have been found to be appealing (Russell \& Worsley, 2013). The foods chosen for each child were based on information provided by his/her parents, and represented a plausible meal, comprising soup, bread, fruit/vegetables and a dessert. Children were given age-appropriate portion sizes and parents were asked to behave in the way they usually would when offering a meal.

The objective was to validate the food fussiness subscale of the CEBQ by observing children's rejection and acceptance of familiar and unfamiliar foods in a naturalistic setting. It was hypothesised that higher scores on the CEBQ FF would be associated with more observed food rejection behaviours and fewer food acceptance behaviours. It was also hypothesised that higher scores on the CEBQ FF will be associated with less consumption of all food types (familiar/appealing, familiar/unappealing, unfamiliar/appealing and unfamiliar/unappealing) and this association is expected to be strongest for unfamiliar/unappealing foods and weakest for familiar/appealing foods. Finally, it was further hypothesized that higher scores on the CEBQ FF will be associated with longer meal duration.

\section{METHOD}

\subsection{Participants}

Sixty-seven mother-child pairs took part in this study. It focused on children aged two to four years as this age range has been found to be associated with increased parent perception of child food fussiness (Carruth et al., 2004; Hafstad et al., 2013). Previous studies in this 
field demonstrate that few fathers typically volunteer to participate in research of this kind (see Patrick \& Nicklas, 2005; Holley, Haycraft \& Farrow, 2017). To avoid the methodological limitation of having a mixed sex parental group, but insufficient fathers for sub-group analysis, it was decided that the eligibility criteria for the study would be mothers and their child aged from two to four years, therefore, only mothers were invited to participate. We acknowledge that this limits the conclusions we can draw from this study and discuss the implications of the decision below. The mean age of children who participated was 3 years ( $\mathrm{S} . \mathrm{D}=1$ year) and the sample consisted of 39 girls and 28 boys. Mothers' age ranged from 22 to 45 years $(M=36$ years; S.D = 5 years); most were well-educated $(65.7 \%$ had an undergraduate or postgraduate degree), the majority described themselves as white British (80.6\%) (OPCS; 2003) and almost all were living with a spouse/partner (92.5\%). Two exclusion criteria were employed. Firstly, because the foods selected for the mealtime observation could contain nuts and dairy, children were excluded if their mother reported diagnosed nut allergies or lactose intolerance. Secondly, children with developmental disorders may have unusual eating habits due to motor problems and/or sensory difficulties and so children were excluded if their mothers reported atypical development or failure to meet developmental milestones.

\subsection{Measures}

Mothers completed a background questionnaire which recorded the child's age and sex (male or female) as well as the mother's ethnicity, marital status, education and age. Maternal ethnicity was evaluated using the Office of Population Censuses and Surveys (OPCS; 2003) 17 group ethnic classification which combines ethnic and national group dimensions (e.g. White Irish, Black African, Asian Pakistan). Marital status was assessed using three categories (single, living with spouse/partner and not living with spouse/partner). Maternal 
education was based on three stages of education in England; primary, secondary and higher. For higher education, the sub- categories were undergraduate and postgraduate degree qualification.

\subsubsection{CEBQ Food Fussiness Subscale CEBQ FF (Wardle et al., 2001)}

The CEBQ FF was used to assess mother's perception of their child's food fussiness. The subscale consists of six statements which evaluate whether the child eats a variety of foods, the child's interest in new foods and how difficult the child is to please with meals e.g. my child decides he/she doesn't like a food, even without tasting it. Three of the six statements which allude to food acceptance, e.g. " $m y$ child is interested in tasting food he/she hasn't tasted before" are reverse coded. Respondents rate on a 5-point Likert scale $(1=$ never, $5=$ always) how applicable each statement is to their child. A global mean score is calculated which can range from one to five with higher scores reflecting greater child food fussiness. The CEBQ FF has been demonstrated as having high reliability with a Cronbach's alpha value of .91 (Wardle et al, 2001). For the current sample, Cronbach's alpha for food fussiness was 0.94 .

\subsubsection{Food Checklist}

A food checklist was created to be completed by mothers with a view to providing a meal that represented a plausible meal (to include soup, fruit/vegetables, bread and dessert), which could be prepared in a standardised way and which was tailored for each child to include appealing and unappealing, familiar and unfamiliar foods. This was to ensure that children participating in the study were offered a meal that comprised liked and disliked, familiar and unfamiliar foods. This classification was done to delineate children's responses to each category. Foods to be included in the list were selected to be appealing or unappealing based on the characteristics of foods reported by parents of fussy eaters as being consistently avoided or preferred (Boquin, Smith-Simpson, Donovan, \& Lee, 2014). Characteristics of 
foods found to be unappealing to fussy eaters include foods with slippery and mushy textures, foods with sour and bitter tastes, food with strong aromas, mixed foods with complex ingredients, soups and most vegetables. Foods that appeal to fussy eaters were found to be sweet, crunchy, salty or have bland and simple flavours. These include desserts, milk, pastries and sweet fruits. The food items included in the checklist are shown in Table 1.

[Table 1 here]

\subsection{Procedure}

Ethical approval for this study was obtained from the local Research Ethics Committee (UREC 15/43/KH). Children were recruited from a university Child Development Group

Database which contains the details of over 2000 families with children in this age group. The database comprised details of families from the Royal Berkshire Hospital in Reading who were invited to participate in future psychological research by joining the University of Reading Infant Panel. Potential participants are recruited via researchers making regular visits to the post-delivery ward, and parents who express an interest are added to the database (at this stage, they are consenting to being approached by researchers in the future). The database is representative of the local population in some respects, for example participants in the present study were predominantly White British (81\%) which is also fairly representative of Reading's demographics.

Mothers were contacted either via email or telephone and given a brief overview of the study as well as the inclusion/exclusion criteria. Out of 375 mothers contacted, 23 confirmed that their child had been diagnosed as lactose intolerant or with nut allergies making them ineligible. Of the 352 eligible mothers, 195 did not respond and a further 68 responded to say that they were unavailable to participate (for example, they had moved out of the area). The remaining 89 mothers ( $25 \%$ of those eligible) agreed to participate and provided an email 
address to receive a demographic and Food Fussiness questionnaire. Of these mothers, 22 did not participate because they could not be available for the observational study. Consistent with Research Ethics Committee directions, mothers were not required to explain nonparticipation in the observational study. Those who chose to so typically gave reasons such as their child being ill or other commitments meaning a convenient time for a home visit could not be arranged. The final sample comprised 67 mothers, $75 \%$ of those who agreed to participate and $19 \%$ of eligible mothers contacted. G*Power 3 (Faul, ErdFelder, Lang, \& Buchner, 2007) was used to establish that the final sample of 67 participants was sufficient to meet Cohen's (1992) power recommendation and yield statistical $\beta$ power of more than 0.80 (based on $\alpha=0.05)$ and to detect medium correlational effects $(r=0.33)$.

When mothers agreed to participate, they were emailed a checklist of nineteen foods and asked to indicate for each food whether their child was likely to find the food familiar and appealing, familiar and unappealing, unfamiliar and appealing or unfamiliar and unappealing. This classification was done to delineate children's responses to each category, as explained above. This was to ensure that children participating in the study were offered a meal that comprised liked and disliked, familiar and unfamiliar foods. To avoid the food checklist influencing their perception of their children's food fussiness, mothers completed the CEBQ before the food checklist. Upon completion of the questionnaire, researchers arranged a convenient date for a home visit. In advance of the home visit, mothers were informed of the food items that the researcher would be bringing for the child's lunch (based on their responses on the food checklist). For each child, the completed checklist was used to select one food for each of the following categories: familiar and appealing; familiar and unappealing; unfamiliar and appealing; or unfamiliar and unappealing). The researcher explained to mothers that their child needed to be observed eating the meal without the influence of family members eating at the same time and were asked to identify a mealtime 
that would be most convenient; either lunch or evening meal. Mothers were asked not to feed their children for two hours prior to the meal with the aim of controlling for hunger.

\subsection{Mealtime Observation}

Children were observed in their homes during a typical meal. On arrival, following greetings, the researcher showed the mother the food items to be prepared for the child and assisted the mother in the meal preparation. Each child was provided with a meal comprising four food items two of which were familiar (appealing and unappealing) and two of which were unfamiliar (appealing and unappealing). An example of a meal might be $100 \mathrm{~g}$ readymade lentil dahl soup (unfamiliar and unappealing), one slice granary bread equivalent to $38 \mathrm{~g}$ (familiar and unappealing), 16 seedless green grapes equivalent to $75 \mathrm{~g}$ (familiar and appealing) and half a custard tart equivalent to $80 \mathrm{~g}$ (unfamiliar and appealing) totalling about $420 \mathrm{kcal}$. To determine the proportion of food that the child had consumed, each portion of food was weighed by the researcher using a Salter digital kitchen weighing scale before it was placed on the child's plate and leftovers were weighed by the researcher after the child had finished eating. The proportion of food consumed was the amount of food eaten relative to the total amount of food presented. For example, if the food given to the child weighed $100 \mathrm{~g}$ before and the leftovers weighed $80 \mathrm{~g}$, meaning the child consumed $20 \mathrm{~g}$, therefore the proportion of food consumed would be $20 / 100$ which is 0.2 . A video camera was used to capture the child's eating behaviour during the meal which was placed on a tripod and positioned in the dining area. To diminish social desirability effects, where the child might be inclined to behave differently because of the video camera, the camera was set up about 15-20 minutes prior to the meal and the researcher made conversation with the child with the intention of familiarising him/her to both the researcher and the video camera. During this time, the child was shown an age appropriate information sheet in the form of cartoon images 
276 depicting the stages of the meal observation. The researcher explained to the child that they

277 were first going to play a game that would be video recorded, thus explaining the presence of

278

279 the camera. The game took place where the child would later eat his/her meal and involved a popular children's card game called "tummy ache". The researcher played this game with the child and the mother until the child felt at ease and was comfortable playing with the researcher alone at which point the mother took the opportunity to leave and prepare the child's meal. If the child was unwilling to play the game or too young to comprehend the game, he/she was invited to do a drawing of their favourite meal or indicate their favourite foods from the pack of cards. When the food had been prepared, the researcher left the room and the mother invited the child to eat. This was to ensure the meal was as typical as possible. Mothers were asked to behave as they usually would during a typical meal, for example, encouraging their child to eat if that is what they would typically do. Although, being seated and eating with their child may have been the norm for some mothers, they were asked not to eat at all, specifically asked not to eat from the presented food so that the amount of food eaten by the child could be accurately calculated. To ensure uniformity between meals, mothers were asked not to add to the meal, for example by offering butter, ketchup, cheese. Recording was stopped when mothers informed the researcher that the child had finished eating. Children were given stickers and thanked for participating while mothers were provided with a leaflet explaining the purpose of the study and thanked for their participation.

\subsection{Coding Eating Behaviour}

Video recordings of mealtimes were coded offline by the researcher using the Observer XT9 Software (http://www.noldus.com/human-behaviourresearch/products/theobserver-xt90). Behavioural measures of food fussiness were obtained from previous literature (Fries et al., 2017; Klesges et al., 1983; Luchini, Lee, \& Donovan, 2016; Timimi, Douglas, \& 
301 Tsiftsopoulou, 1997) which lists several mealtime behaviours that have been found to be

302

303

304

305

306

307

308

309

310

311

312

313

314

315

316

317

318

319

320

321

associated with fussy eaters (see Table 2). As there was not an existing coding scheme that included all these behaviours together, one was adapted by integrating features from previously used coding schemes (e.g., Klesges et al., 19983; Luchini et al., 2016; Fries et al., 2017) and included a detailed description of the behaviours to be coded from the video recordings. The final inclusion of behaviours was informed by several pilot coding sessions. ${ }^{1}$ Each behaviour was assigned a keyboard key and every time a particular behaviour was observed, it was scored by pressing the corresponding keyboard key. A second coder was trained by the first author until interrater reliability reached (calculated using the Observer XT9 software interrater reliability function) 90\% agreement (Cohens $k=0.896, \mathrm{p}<0.01$ ). The second coder subsequently coded $25 \%$ of the videos and reliability was high (percentage agreement between coders ranged from 79 - 92\%).

[Table 2 here]

\subsection{Data Analysis}

The hypotheses and the data analytic plan were made prior to data collection and all data driven analyses are clearly identified and discussed accordingly. Correlation analyses were performed to test the hypotheses. Data were analysed using Statistical Package for Social Sciences (SPSS), version 23. Descriptive statistics were first computed. An examination of the normal probability plot and the histogram showed that the study variables were skewed and not normally distributed. Significant Shapiro-Wilk's tests for normality on all variables further indicated the violation of the assumption of normality making the data set unsuitable

\footnotetext{
${ }^{1} \mathrm{We}$ acknowledge that child temperament in relation to child feeding is an important consideration and initially considered coding for emotional intensity such as crying and throwing tantrums as observed in a previous study (Fries et al, 2017). These behaviours, however, were not observed in any our pilot observations. Reviewing the videos, it can be confirmed it was rarely seen across our observations, and where it was observed, it was captured via existing codes.
} 
for parametric analysis. The distribution of the variables was not improved using log, reciprocal or square root transformations, therefore a bootstrapping procedure to generate a 95\% bias- corrected bootstrapped confidence intervals of the correlation coefficients (1000 samples, $N=67$ ) was performed to test the study hypotheses. For child and maternal sociodemographic variables measured on a continuous scale (child age and maternal age), initial bootstrapped two-tailed Pearson's correlation analyses were conducted to check for significant associations between these variables with observed mealtime behaviours and food fussiness. For dichotomous child and maternal sociodemographic variables (chid sex, maternal education, marital status and maternal ethnicity), bootstrapped independent samples t-tests were used to check if observed mealtime behaviours and food fussiness significantly differed by group. Significance levels were set at $p<.05$. Results indicated that the continuous sociodemographic variables were not significantly related to the study variables. For the dichotomous sociodemographic variables, results indicated that there was no significant difference between groups for observed mealtime behaviours and food fussiness. Therefore, sociodemographic variables were not included in further analyses (see Tables 1 and 2 in supplementary materials).

\subsubsection{Relationships between observed mealtime behaviours}

To explore relationships between observed mealtime behaviours, preliminary two -tailed bootstrapped Pearson's partial correlations controlling for mealtime duration were performed (see Table 3). An alpha of $p<0.05$ was adopted for the analyses. Positive and negative child food comments were adjusted for total utterances by calculating a proportion score for positive and negative comments i.e. proportion of negative comments = negative comments/ (negative + positive comments). Results indicated that the majority of the mealtime observations associated with food rejection and avoidance namely food refusal, spitting out food, playing with food, licking food, touching food and child negative food comments were 
all significantly positively correlated. The exception was smelling food followed by rejection, which was only significantly associated with food refusal, licking food and spitting food. However, like the majority of the behaviours associated with food rejection and avoidance, smelling food followed by rejection was significantly negatively related to mealtime behaviours associated with food acceptance. It was therefore decided to include smelling followed by food rejection as a food rejection mealtime behaviour.

The results also indicated a significant positive relationship between the mealtime behaviours associated with food acceptance i.e. food consumption and child positive food comments.

\subsubsection{Exploring relationships between CEBQ FF, observed mealtime behaviours and proportion of foods consumed}

To test our main hypothesis, two-tailed bootstrapped Pearson's partial correlation analyses controlling for meal duration were used to investigate the relationship between mothers' responses on the CEBQ FF with observed food rejection and food acceptance mealtime behaviours, proportion of familiar/appealing, familiar/unappealing, unfamiliar/appealing and unfamiliar/unappealing foods consumed. Two tailed bootstrapped correlation analysis was also used to explore the relationships between maternal reported food fussiness and meal duration. Significance levels were set at $\mathrm{p}<0.05$.

\section{RESULTS}

Descriptive statistics for all measures and observed behaviours are displayed in Table 4. Mean scores on the CEBQ FF subscale for children in the current sample reflect those obtained from similar samples (e.g., de Barse et al., 2016; Holley, Farrow, \& Haycraft, 2016). [Table 3 here] 
[Table 4 here]

As indicated in Table 5, bootstrapped Pearson's partial correlation analyses revealed that maternal report of food fussiness was significantly positively correlated with the majority of mealtime behaviours associated with food rejection i.e. spitting food, playing with food, touching food, licking food, child negative food comments and food refusal. There was no correlation between maternal reported food fussiness and smelling food followed by rejection. Maternal reports of food fussiness were significantly negatively correlated to mealtime behaviours associated with food acceptance i.e. food consumption and child positive food comments. There was a significant negative correlation between maternal reports of food fussiness and the proportion of familiar/appealing foods consumed by the child. There was no significant correlation between maternal reported food fussiness and the proportion of familiar/unappealing foods, unfamiliar/appealing foods and unfamiliar /unappealing foods consumed. The correlation between maternal reported food fussiness and meal duration was also not significant which is included in Table 6 together with the correlations between meal duration and mealtime behaviours

[Table 5 here]

[Table 6 here]

\section{DISCUSSION}

The present study aimed to validate maternal reported child food fussiness using the Food Fussiness subscale of the CEBQ against independent observations of children's eating behaviour. Supporting the hypothesis, the results indicated that children whose mothers 
400

401

402

403

404

405

406

407

408

409

410

411

412

413

414

415

416

417

418

419

420

421

422

423

424

reported greater levels of food fussiness exhibited more mealtime behaviours associated with food rejection and fewer mealtime behaviours associated with food acceptance. Maternal reported food fussiness was associated with more spitting food, touching food, licking food, food refusal, playing with food and more negative food comments by the child. Maternal reported food fussiness was also associated with less food consumption and fewer positive food comments by the child. This is consistent with previous findings where children categorised as fussy eaters have been reported to display more food rejection behaviours and less food acceptance behaviours during mealtimes in comparison to non-fussy eaters (e.g., Fries et al., 2017; Fernandez et al., 2018). Maternal reported food fussiness was not associated with smelling food followed by rejection contrary to the hypothesis.

In addition, as expected, children whose mothers reported greater levels of food fussiness consumed smaller proportions of familiar/appealing foods during the observed mealtime.

However, the finding of a non-significant correlation between maternal reported food fussiness and the proportion of other food types consumed (i.e. familiar/unappealing, unfamiliar/appealing and unfamiliar/unappealing) does not support the hypothesis. These findings are contrary to the expectation of the strongest association between CEBQ FF scores and less consumption of unfamiliar/unappealing foods and weakest for familiar/appealing foods. Our findings show that the opposite- that maternal reported food fussiness is only associated with less consumption of familiar and appealing foods. These findings make sense given that children are considered fussy because they tend to dislike and refuse foods that children would usually eat. It is not unusual for children to refuse foods which are unfamiliar and unappealing to most children such as spinach and broccoli and they would not be labelled as fussy eaters as a result. Non-significant findings between maternal reported food fussiness and the proportion of familiar/unappealing and unfamiliar/unappealing foods consumed can also be attributed to floor effects, as the data indicate that children did not consume enough of 
these food types for associations with food fussiness to be found (See figure 1 in supplementary material). This is plausible given that children regardless of whether they are fussy eaters are less likely to consume familiar and unfamiliar foods they consider to be unappealing.

Also contrary to expectations and to previous research where parents of fussy eaters have described their children as slow eaters who usually have prolonged feeding times (e.g., Reau, Senturia, Lebailly, \& Christoffel, 1996; Timimi et al, 1997), the present study found that maternal reported food fussiness was not associated with mealtime duration. This finding is consistent with those of previous studies that have used observational approaches to investigate meal duration in fussy eaters (e.g., Fries et al., 2017; Jacobi, Agras, Bryson, \& Hammer, 2003). It should be noted that studies that have found lengthened mealtimes to be a behavioural indicator of food fussiness have relied on parent-report. It is possible that the associations found in these studies may be explained by parents perceiving the mealtime as lasting longer because of their struggles to encourage food consumption. A possible explanation for the lack of association between food fussiness and meal duration in this study may be that fussy children rejected most of the food offered, curtailing the duration of the meal. In contrast, some less fussy children might have spent more time consuming the food, resulting in longer meal duration. The significant positive association between food consumption and mealtime duration in the present study as indicated in Table 6 lends support to this argument. In the present study, as mothers were asked to sit with their child during the meal, it is also possible that their expectations of whether their child was likely to consume the food might have affected the meal duration. For instance, it was observed that some mothers expected their children to eat some of the food and used verbal prompts and some pressure to encourage, resulting in longer meal durations. Other mothers did not expect their children to consume all/any of the food, did not encourage consumption, and did not resist 
when the child refused the meal, thus ending the mealtime quickly. There is also the possibility that if mothers had provided and prepared the foods, they would have expected their child to like it and therefore used more strategies to encourage food consumption leading to longer meal durations. In the present context, however, mothers may have had no expectations for their child to consume the food given that it was provided and prepared by the researchers, therefore did not encourage food consumption when the child refused to eat resulting in shorter meal durations.

Mealtime food rejection behaviours found to be associated with food fussiness in previous studies (e.g., Boquin, Smith-Simpson, Donovan, \& Lee, 2014; Fries et al,, 2017; Klesges et al., 1983) were also observed in this study. Children were observed playing with food, verbally and physically refusing food, spitting food out, touching and licking food without consuming it and making negative comments about food. The non-significant association between smelling food followed by rejection and maternal reports of food fussiness in the present study is consistent with the findings of previous studies where smelling food was found to be unrelated to parent-reported food fussiness (e.g., Johnson, Davies, Boles, Gavin \& Bellows, 2015; Momin et al., 2018). However, while smelling food has been reported to occur infrequently during mealtimes (e.g., Blissett, Bennett, Donohoe, Rogers, \& Higgs, 2012), the present study found that smelling food occurred quite frequently during the mealtime observation. Children were observed to display this behaviour on occasions that led to both food rejection and food acceptance. Smelling followed by food rejection, however, was observed to occur more frequently than smelling followed by food acceptance and was found to be significantly negatively related to food acceptance behaviours i.e. food consumption and child positive food comments as indicated in Table 3. It is possible that smelling food may have been used as an exploratory strategy by children who were suspicious of some unfamiliar foods. Fussy eaters aged 2-5 years have been observed to 
become suspicious and inspect food during mealtimes by touching and licking presented food (e.g., Boquin, Smith-Simpson, Donovan, \& Lee, 2014; Luchini et al., 2016). In the present study, children's decision to accept or reject food following smelling may have been dependent on how appealing or unappealing they found the smell, with appealing smells resulting in food acceptance and unappealing smells in food rejection. While this proposed pattern could not be confirmed in the present study, future replications could determine whether smelling followed by food acceptance or food rejection is related to different foods, particularly foods children find appealing and unappealing. Given the findings of significant associations with food rejection and food acceptance behaviours, as well as its frequent occurrence during the observed meal, more research exploring smelling food as an important mealtime behaviour associated with food fussiness is warranted.

The main strength of this study is its use of a behavioural observation approach to explore children's eating behaviours in a naturalistic environment. This approach permitted objective measurement of the mealtime behaviours associated with food fussiness and offered insight into how maternal reported food fussiness relates to actual child mealtime behaviour.

Observing children in their home environment, where they are likely to feel most at ease, minimises changes to behaviour that can arise in unfamiliar settings. Providing children with age-appropriate portion sizes representative of a plausible meal is another strength of this study and an improvement from methods where children's recommended portion sizes have been exceeded (e.g., Jacobi et al., 2003). Including familiar and unfamiliar foods from several food groups i.e. bread, vegetables, fruits, dessert, soup was an opportunity to observe how children approach a range of foods and provided the opportunity to observe food fussiness more broadly. This is an improvement from methods where familiar and unfamiliar foods have been limited to one food group (e.g., Fernandez et al., 2018). 
499 Some limitations should be noted. First, the presence of the camera during the recorded mealtime was likely to have affected children's behaviours. Although measures were taken to ensure the child became accustomed to the presence of the camera before the mealtime observation commenced, many children remained aware of its presence and this may have altered their typical behaviours. Future replication where video-recording is unobtrusive would address this limitation. Second, observation of children's eating behaviours was limited to a single meal and it cannot be determined if the observed behaviours were typical of the child. For example, some mothers commented on their child's unusual response to some of the presented foods, for example "he/she usually likes avocados". Observing a particular behaviour multiple times provides a more accurate representation (Young \& Drewett, 2000), therefore future research observing children on several occasions will help improve reliability. Third, on reflection, offering all the food items at once is not representative of a typical meal as children are not usually given their main meal together with a dessert; indeed several mothers commented that they would not usually serve dessert with the main meal. It is plausible that offering the dessert at the same time as the rest of the food may have influenced children's decision to try the other food items. On subsequent examination of the video recordings, it was observed that many children's attention was initially drawn to the dessert as they found this most appealing. These children typically consumed the dessert first and were then reluctant to try the other food items. It is unclear, therefore, how children would have responded to these foods in the absence of the dessert.

519 Replication of this study where desserts are not included with other food items would help provide a more accurate assessment of children's responses to familiar and unfamiliar food items. Fourth, mothers were informed of the food items that the researcher brought for the child's lunch prior to the mealtime observation (based on their responses on the food checklist). Although it seems unlikely, it is possible that some mothers might have 
subsequently exposed their children to some novel foods which may have influenced their children's responses to these foods during the observation. Future replications where mothers are not informed of the food their child will be eating during the observation would address this limitation. Fifth, the current study measured the frequencies of mealtime behaviours without accounting for their duration. For example, playing with food for 3 seconds was scored identically to playing with food for 15 seconds which is a limitation. However, as we were interested in the relationship between higher scores on the CEBQ FF and the number of occurrences of food rejection and acceptance behaviours during the recorded mealtime, measuring the presence or absence of a behaviour seemed more relevant that measuring its duration. Sixth, this study did not include a measure of neophobia which is a limitation given that children were asked to try unfamiliar foods. The inclusion of a food neophobia measure would have ascertained whether children with high food neophobia scores displayed more food rejection mealtime behaviours with unfamiliar foods. In addition, as food neophobia and food fussiness are considered as two separate constructs (Dovey et al., 2008), the inclusion of a food neophobia measure would have been useful to ascertain whether mothers conceptually differentiate between food fussiness and food neophobia. Such information would help determine if a mother's perception of food neophobia in her child also extends to the categorization of the child as a fussy eater on the CEBQ FF. Future replications would therefore benefit from an inclusion of a measure of food neophobia. Seventh, as is typical of research in this field (e.g., Powell, Farrow \& Meyer, 2011; Farrow \& Coulthard, 2012; Haycraft, Farrow \& Blissett, 2013; Holley et al., 2017) the present findings cannot be generalised beyond the predominantly White British, well-educated mothers from two-parent households who agreed to participate in this study. The characteristics of our sample highlight the difficulty of recruiting participants with more diverse socio-demographic characteristics to research studies. Future studies should seek to replicate the findings with 
549 other socio-demographic groups. For the reasons given above, fathers were not recruited to 550 this study. This is typical of research in this field as participants in most studies using the

551 CEBQ FF have been predominantly or exclusively mothers (e.g., Holley et al., 2017;

552 Fernandez et al., 2018) either as a result of explicit inclusion criteria or because fathers are 553 less likely to participate in research of this kind. While validating the subscale for mothers is 554 of merit, it is important for research in this field to engage with fathers and their experiences 555 of children's eating. This remains challenging given difficulty recruiting fathers into research 556 as there have been reports of response rates of less than $10 \%$ from fathers when completing 557 questionnaires directed at parents/caregivers (e.g., Patrick \& Nicklas, 2005; Wardle, Carnell $558 \&$ Cooke, 2005). Finally, it should be noted that some mothers used some prompts to encourage food consumption in their children during the mealtime observation. It is possible that the use of prompts may have influenced child behaviour such that food refusal was in response to maternal control and not in response to the trait of food fussiness. Although this material falls beyond the scope of the present study which focuses on validating the CEBQ, further research investigating the relationship between maternal prompts and food fussiness is required.

\section{CONCLUSIONS}

Overall, the correspondence between independent observations of children's food rejection and acceptance behaviours with maternal reports of food fussiness suggests that mothers provide accurate and reliable information regarding their children's eating behaviour. These findings are plausible as mothers are often the main caregivers and tend to spend considerable time with their children in various settings, including mealtimes (Carnell 
575 of child eating to be a reliable reflection of independent observations (e.g., Carnell \& Wardle, 576 2007; Fernandez et al., 2018) while improving on previous methods by observing children in

577 a naturalistic setting and including a variety of foods. Importantly, these results validate the

578 Food Fussiness subscale of the CEBQ as an accurate measure of child food fussiness that can

579 be used by researchers and health practitioners with confidence.

580

581

582

583

584

585

586

587

588

589

590 All authors have reviewed and approved the complete manuscript and accept full

591 responsibility for all aspects of the work described.

592 This research did not receive any specific grant from funding agencies in the public,

593 commercial, or not-for-profit sectors.

594 Declarations of interest: none 
595

596

597

598

599

600

601

602

603

604

605

606

607

608

609

610

611

612

613

614

615

616

617

618

619

\section{REFERENCES}

Blissett, J., Bennett, C., Donohoe, J., Rogers, S., \& Higgs, S. (2012). Predicting Successful Introduction of Novel Fruit to Preschool Children. Journal of the Academy of Nutrition and Dietetics, 112(12), 1959-1967. https://doi.org/10.1016/j.jand.2012.08.014

Boquin, M. M., Moskowitz, H. R., Donovan, S. M., \& Lee, S. Y. (2014). Defining perceptions of picky eating obtained through focus groups and conjoint analysis. Journal of Sensory Studies. https://doi.org/10.1111/joss.12088

Boquin, M., Smith-Simpson, S., Donovan, S. M., \& Lee, S. Y. (2014). Mealtime Behaviors and Food Consumption of Perceived Picky and Nonpicky Eaters through Home Use Test. Journal of Food Science, 79(12), M2523-S2532. https://doi.org/10.1111/1750-3841.12698 Carnell, S., \& Wardle, J. (2007). Measuring behavioural susceptibility to obesity: Validation of the child eating behaviour questionnaire. Appetite, 48(1), 104-113.

https://doi.org/10.1016/j.appet.2006.07.075

Carruth, B. R., Skinner, J., Houck, K., Moran, J., Coletta, F., \& Ott, D. (1998). The phenomenon of "picky eater": a behavioral marker in eating patterns of toddlers. Journal of the American College of Nutrition. https://doi.org/10.1080/07315724.1998.10718744

Carruth, B.R., Ziegler, P. J., Gordon, A., \& Barr, S. I. (2004). Prevalence of picky eaters among infants and toddlers and their caregivers' decisions about offering a new food. Journal of the American Dietetic Association, 104(SUPPL. 1), 57-64.

https://doi.org/10.1016/j.jada.2003.10.024

Cohen, J. (1992). A power primer. Psychological Bulletin, 112(1), 155.

Cooper, P. J., Whelan, E., Woolgar, M., Morrell, J., \& Murray, L. (2004). Association between childhood feeding problems and maternal eating disorder: Role of the family environment. British Journal of Psychiatry, 184(MAR.), 210-215.

https://doi.org/10.1192/bjp.184.3.210 
620 de Barse, L. M., Cano, S. C., Jansen, P. W., Jaddoe, V. V. W., Verhulst, F. C., Franco, O. H.,

621 ... Tharner, A. (2016). Are parents' anxiety and depression related to child fussy eating?

622

623

624

625

626

627

628

629

630

631

632

633

634

635

636

637

638

639

640

641

642

643

644

Archives of Disease in Childhood, 101(6). https://doi.org/10.1136/archdischild-2015-309101

Dovey, T. M., Staples, P. A., Gibson, E. L., \& Halford, J. C. G. (2008). Food neophobia and “picky/fussy" eating in children: A review. Appetite.

https://doi.org/10.1016/j.appet.2007.09.009

Farrow, C. V., \& Coulthard, H. (2012). Relationships between sensory sensitivity, anxiety and selective eating in children. Appetite, 58(3), 842-846.

https://doi.org/10.1016/j.appet.2012.01.017

Faul, F., ErdFelder, E., Lang, a.-G., \& Buchner, a. (2007). A Flexible statistical power analysis program for the social, behavioral, and biomedical sciences. Behavioral Research Methods, 39(2), 175-191. https://doi.org/10.3758/BF03193146

Fernandez, C., DeJesus, J. M., Miller, A. L., Appugliese, D. P., Rosenblum, K. L., Lumeng, J. C., \& Pesch, M. H. (2018). Selective eating behaviors in children: An observational validation of parental report measures. Appetite, 127(May), 163-170. https://doi.org/10.1016/j.appet.2018.04.028

Fries, L. R., Martin, N., \& van der Horst, K. (2017). Parent-child mealtime interactions associated with toddlers' refusals of novel and familiar foods. Physiology and Behavior, 176, 93-100. https://doi.org/10.1016/j.physbeh.2017.03.001

Galloway, A. T., Fiorito, L., Lee, Y., \& Birch, L. L. (2005). Parental pressure, dietary patterns, and weight status among girls who are "picky eaters." Journal of the American Dietetic Association, 105(4), 541-548. https://doi.org/10.1016/j.jada.2005.01.029

Goh, D. Y., \& Jacob, A. (2012). Perception of picky eating among children in Singapore and its impact on caregivers: a questionnaire survey. Asia Pacific Family Medicine, 11(1), 5. https://doi.org/10.1186/1447-056X-11-5 
645 Hafstad, G. S., Abebe, D. S., Torgersen, L., \& von Soest, T. (2013). Picky eating in preschool 646 children: The predictive role of the child's temperament and mother's negative affectivity. 647 Eating Behaviors, 14(3), 274-277. https://doi.org/10.1016/j.eatbeh.2013.04.001

648 Haycraft, E., Farrow, C., Meyer, C., Powell, F., \& Blissett, J. (2011). Relationships between 649 temperament and eating behaviours in young children. Appetite, 56(3), 689-692. 650 https://doi.org/10.1016/j.appet.2011.02.005

651 Haycraft, E.L., Farrow, C. \& Blissett, J. (2013). Maternal symtoms of depression are related 652 to observations of controlling feeding practices in mothers of young children. Journal of 653 Family Psychology, 27 (1), 159-164.

654 Hendy, H. M., Williams, K. E., Riegel, K., \& Paul, C. (2010). Parent mealtime actions that 655 mediate associations between children's fussy-eating and their weight and diet. Appetite, 656 54(1), 191-195. https://doi.org/10.1016/j.appet.2009.10.006

657 Holley, C. E., Farrow, C., \& Haycraft, E. (2016). Investigating the role of parent and child 658 characteristics in healthy eating intervention outcomes. Appetite, 105, 291-297. https://doi.org/10.1016/j.appet.2016.05.038 Holley, C.E., Haycraft, E., \& Farrow, C. (2017). Predicting Children's Fussiness with vegetables: The role of feeding practices. Maternal and Child Nutrition, 14. https://doi: $10.1111 / \mathrm{mcn} .12442$ Jacobi, C., Agras, W. S., Bryson, S., \& Hammer, L. D. (2003). Behavioral validation, precursors, and concomitants of picky eating in childhood. Journal of the American Academy of Child and Adolescent Psychiatry, 42(1), 76-84. https://doi.org/10.1097/00004703200306000-00025

667 Jansen, P. W., Roza, S. J., Jaddoe, V. W., Mackenbach, J. D., Raat, H., Hofman, A., ... 668 Tiemeier, H. (2012). Children's eating behavior, feeding practices of parents and weight 669 problems in early childhood: results from the population-based Generation R Study. The 
670

671

672

673

674

675

676

677

678

679

680

681

682

683

684

685

686

687

688

689

690

691

692

693

694

International Journal of Behavioral Nutrition and Physical Activity, 9(1), 130.

https://doi.org/10.1186/1479-5868-9-130

Johnson, S. L., Davies, P. L., Boles, R. E., Gavin, W. J., \& Bellows, L. L. (2015). Young

Children's Food Neophobia Characteristics and Sensory Behaviors Are Related to Their

Food Intake. Journal of Nutrition, 145(11). https://doi.org/10.3945/jn.115.217299

Klesges, R. C., Coates, T. J., Brown, G., Sturgeon-Tillisch, J., Moldenhauer-Klesges, L. M., Holzer, B., ... Vollmer, J. (1983). Parental influences on children's eating behavior and relative weight. Journal of Applied Behavior Analysis, 16(4), 371-378.

https://doi.org/10.1901/jaba.1983.16-371

Luchini, V., Lee, S. Y., \& Donovan, S. (2016). Observed differences in child picky eating behaviors between the child's home and centre-or home-based childcare. FASEB Journal, 30 (1). https://doi.org/10.1016/j.appet.2017.04.021

Momin, S. R., Hughes, S. O., Elias, C., Papaioannou, M. A., Phan, M., Vides, D., \& Wood, A. C. (2018). Observations of Toddlers' sensory-based exploratory behaviors with a novel food. Appetite, 131(August), 108-116. https://doi.org/10.1016/j.appet.2018.08.035

Office of Population Censuses and Surveys (2003). Census Ethnic Group and Country of Birth (Census User Guide No. 9). London: HMSO

Patrick, H, \& Nicklas, T. A. (2005). A review of family and social determinants of children's eating patterns and diet quality. Journal of the American College of Nutrition, 24(2), 83-92. https://doi.org/24/2/83

Powell, F. C., Farrow, C. V., \& Meyer, C. (2011). Food avoidance in children. The influence of maternal feeding practices and behaviours. Appetite, 57(3), 683-692.

https://doi.org/10.1016/j.appet.2011.08.011

Ramsay, M., Martel, C., Porporino, M., \& Zygmuntowicz, C. (2011). The Montreal children's hospital feeding scale: A brief bilingual screening tool for identifying feeding 
695

696

697

698

699

700

701

702

703

704

705

706

707

708

709

710

711

712

713

714

715

716

717

718

719

problems. Paediatrics and Child Health, 16(3), 147-151.

https://doi.org/10.1093/pch/16.3.147

Reau, N. R., Senturia, Y. D., Lebailly, S. A., \& Christoffel, K. K. (1996). Infant and toddler feeding patterns and problems: Normative data and a new direction. Journal of

Developmental and Behavioral Pediatrics, Vol. 17, pp. 149-153.

https://doi.org/10.1097/00004703-199606000-00002

Rogers, S., Ramsey, M., \& Blissett, J. (2018). The Montreal's children hospital feeding scale: Relationship with parental report of child feeding behaviours and observed feeding interactions. Appetite, 125, 201-209.

Russell, C.G. \& Worsley, A. (2013). Why don't they like that? And can I do anything about it? The nature and correlates of parents' attributions and self-efficacy beliefs about preschool children's food preferences. Appetite, 66, 34-43.

Steinsbekk, S., Hamre Sveen, T., Fildes, A., Llewellyn, C., \& Wichstrøm, L. (2017).

Screening for pickiness -- a validation study. International Journal of Behavioral Nutrition \& Physical Activity, 14, 1-4. https://doi.org/10.1186/s12966-016-0458-7

Surette, V., Ward, S., Morin, P., Vatanparast, H., \& Bélanger, M. (2017). Food Reluctance of Preschool Children Attending Daycare Centers Is Associated with a Lower Body Mass Index. Journal of the Academy of Nutrition and Dietetics, 117(11), 1749-1756.

https://doi.org/10.1016/j.jand.2017.07.007

Tharner, A., Jansen, P. W., Kiefte-de Jong, J. C., Moll, H. a., Hofman, A., Jaddoe, V. W. V., ... Franco, O. H. (2015). Bidirectional Associations between Fussy Eating and Functional Constipation in Preschool Children. The Journal of Pediatrics, 166(1), 91-96.e1. https://doi.org/10.1016/j.jpeds.2014.09.028

Timimi, S., Douglas, J., \& Tsiftsopoulou, K. (1997). Selective eaters: a retrospective case note study. Child: Care, Health and Development, 23(3), 265-278. 
720

721

722

723

724

725

726

727

728

729

730

731

732

733

734

735

736

737

738

739

740

van der Horst, K. (2012). Overcoming picky eating. Eating enjoyment as a central aspect of children's eating behaviors. Appetite, 58(2), 567-574.

https://doi.org/10.1016/j.appet.2011.12.019

van der Horst, K., Eldridge, A., Deming, D., \& Reidy, K. (2014). Caregivers’ perceptions about picky eating: associations with texture acceptance and food intake (379.3). The FASEB Journal, 28(1_supplement), 373-379.

Vermeer, H. J., \& van IJzendoorn, M. H. (2006). Children's elevated cortisol levels at daycare: A review and meta-analysis. Early Childhood Research Quarterly, 21(3), 390-401. https://doi.org/10.1016/j.ecresq.2006.07.004

Wardle, J., Guthrie, C. A., Sanderson, S., \& Rapoport, L. (2001). Development of the Children's Eating Behaviour Questionnaire. Journal of Child Psychology and Psychiatry, and Allied Disciplines, 42(7), 963-970. https://doi.org/10.1111/1469-7610.00792

Wardle, J., Carnell, S., \& Cooke, L. (2005). Parental control over feeding and children's fruit and vegetable intake: How are they related? Journal of the American Dietetic Association, 105(2), 227-232. https://doi.org/10.1016/j.jada.2004.11.006

Werthmann, J., Jansen, A., Havermans, R., Nederkoorn, C., Kremers, S., \& Roefs, A. (2015). Bits and pieces. Food texture influences food acceptance in young children. Appetite, 84, 181-187. https://doi.org/10.1016/j.appet.2014.09.025

Young, B., \& Drewett, R. (2000). Eating behaviour and its variability in 1-year-old children. Appetite, 35(2), 171-177. 
741

742

\begin{tabular}{|c|c|}
\hline Soups & Wholegrain Breads \\
\hline Sainsbury's Thai beetroot soup & Tesco Rye Bread \\
\hline Sainsbury's Petits pois and ham soup & Hovis Country Granary Bread \\
\hline Sainsbury's lentil dahl soup & Tesco Walnut Loaf \\
\hline Desserts & Fruits and Vegetables \\
\hline Tesco free crème caramel dessert & Grapes \\
\hline Sainsbury's mango and coconut panna cotta & Pears \\
\hline Tesco custard tarts & Gooseberry \\
\hline Waitrose pistachio flavour macaroons & Carrots \\
\hline Tesco profiteroles & Sweetcorn \\
\hline Asda Kulfi-ice pistachio ice cream & Avocado \\
\hline
\end{tabular}

$\underline{\text { Table 1: List of food items included in food checklist }}$

Soups

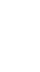


746 Table 2: List of behaviours coded from the mealtime observation

\begin{tabular}{ll}
\hline Observed Mealtime Behaviours & Description of Behaviour (References) \\
\hline Food Refusal & $\begin{array}{l}\text { The child refuses the presented food by pushing the } \\
\text { food away, turning their head away when the food is } \\
\text { presented by the parent, ignoring the presented food or } \\
\text { by verbally refusing to try the food. }\end{array}$ \\
\hline Spitting food & The child places the food in their mouth and spits it out \\
& or vomits. ${ }^{1,3,5,9,10}$ \\
\hline Playing with food & The child plays with food by messing, stirring, throwing \\
& $\begin{array}{l}\text { and crumbling the food or treating the food as well as } \\
\text { the utensils as a toy but does not consume the food. }{ }^{2,3,8}\end{array}$ \\
\hline Licking food & $\begin{array}{l}\text { The child licks the presented food but does not consume } \\
\text { it. }{ }^{8,9}\end{array}$
\end{tabular}

Touching food

The child touches the presented food but does not consume it. ${ }^{8,9}$

\begin{tabular}{ll}
\hline $\begin{array}{l}\text { Smelling food followed by } \\
\text { rejection }\end{array}$ & $\begin{array}{l}\text { The child smells the presented food and refuses to } \\
\text { consume it. }\end{array}$ \\
\hline Child Positive food comments & $\begin{array}{l}\text { Positive sounds and comments the child expresses } \\
\text { towards the presented food, e.g. "I like this", "this tastes } \\
\text { nice", and "yum!" }\end{array}$ \\
\hline Child negative food comments & $\begin{array}{l}\text { Negative sounds and comments the child expresses } \\
\text { towards the presented food. This includes complaints } \\
\text { and expressions of disgust, e.g. "this tastes disgusting", } \\
\text { "Yuk!"9 }\end{array}$ \\
\hline Food consumption & $\begin{array}{l}\text { The child consumes the presented food; putting food in } \\
\text { the mouth and swallowing it } 4,6,8 .\end{array}$ \\
\hline
\end{tabular}


Note: Previous studies that have cited the above mealtime behaviours associated with food fussiness.

1. Klesges et al. (1983); 2. Sanders et al. (1993); 3. Timimi et al. (1997); 4. Jacobi et al. (2003); 5. Lewinsohn et al. (2005); 6. Galloway et al., (2005); 7. Dovey et al. (2008); 8. Boquin, Smith-Simpson, Donovan, \& Lee, (2014); 9. Luchini et al. (2016); 10. Fries et al., (2017). 
Validation of the CEBQ FF

34

Table 3: Two tailed bootstrapped Pearson's partial correlations between observed mealtime behaviours

\begin{tabular}{|c|c|c|c|c|c|c|c|c|c|}
\hline $\begin{array}{l}\text { Food } \\
\text { Refusal }\end{array}$ & $\begin{array}{l}\text { Spitting } \\
\text { food }\end{array}$ & $\begin{array}{l}\text { Licking } \\
\text { Food }\end{array}$ & $\begin{array}{l}\text { Touching } \\
\text { food }\end{array}$ & $\begin{array}{l}\text { Smelling } \\
\text { food } \\
\text { followed by } \\
\text { rejection }\end{array}$ & $\begin{array}{l}\text { Child } \\
\text { negative } \\
\text { food } \\
\text { comments }\end{array}$ & $\begin{array}{l}\text { Maternal } \\
\text { positive } \\
\text { comments }\end{array}$ & $\begin{array}{l}\text { Maternal } \\
\text { negative } \\
\text { comments }\end{array}$ & $\begin{array}{l}\text { Food } \\
\text { Consumption }\end{array}$ & $\begin{array}{l}\text { Child positive } \\
\text { food } \\
\text { comments }\end{array}$ \\
\hline
\end{tabular}

Spitting food

$\begin{array}{lll}\text { Playing with food } & .54 * * & .71 * *\end{array}$

Licking food

$.42 * * \quad .50 * *$

Touching food

$.60 * *$

$.27 *$

$.20 *$

Smelling food

followed by rejection

Child negative food

$.30 *$

$.42 *$

$.25^{*}$

.14

comments

Maternal positive

food comments

$.63^{*}$

$56 * * \quad .28 *$

$.67 * *$

.13

Maternal negative

$.37 *$

$.33 *$

.09

$44 * *$

$-.005$

$.59 * *$

food comments

Food Consumption

$-.06$

$-.10$

.03

$-.18$

.005

.13

$-.19$

Child positive food

$-44 * * \quad-.50 * *$

$-.14$

$-.31^{*} \quad-.34^{* *}$

$-.12$

$-.09$

comments

.01

$-.36^{* *} \quad .14$

$.30 *$

$-.05$

$.33 * *$

Meal duration included as a covariate $* \mathrm{p}<0.05, * * \mathrm{p}<0.001$ 
Table 4: Descriptive statistics for food fussiness and observed mealtime behaviours.

\begin{tabular}{|c|c|c|c|}
\hline Measure & Median (IQR) & Mean (SD) & Min/Max \\
\hline CEBQ FF score & $3.00(1.30)$ & $3.00(1.00)$ & $1.00 / 5.00$ \\
\hline Food refusal & $6.00(9.00)$ & $8.00(5.60)$ & $1.00 / 22.00$ \\
\hline Spitting food & $0.00(2.00)$ & $2.00(3.50)$ & $0.00 / 16.00$ \\
\hline Playing with food & $0.00(2.00)$ & $1.90(3.20)$ & $0.00 / 15.00$ \\
\hline Licking food & $2.00(3.00)$ & $2.00(2.30)$ & $0.00 / 9.00$ \\
\hline Touching food & $4.00(4.00)$ & $4.00(3.40)$ & $0.00 / 16.00$ \\
\hline $\begin{array}{l}\text { Smelling food followed } \\
\text { by rejection }\end{array}$ & $1.00(2.00)$ & $1.50(1.30)$ & $0.00 / 15.00$ \\
\hline Food consumption & $25.00(14.00)$ & $27.00(13.00)$ & $5.00 / 66.00$ \\
\hline $\begin{array}{l}\text { Child negative food } \\
\text { comments }\end{array}$ & $4.00(8.00)$ & $7.00(5.50)$ & $0.00 / 21.00$ \\
\hline $\begin{array}{l}\text { Child positive food } \\
\text { comments }\end{array}$ & $5.00(6.00)$ & $6.00(4.20)$ & $0.00 / 17.00$ \\
\hline $\begin{array}{l}\text { Maternal negative food } \\
\text { comments }\end{array}$ & $0.00(0.00)$ & $0.03(0.17)$ & $0.00 / 1.00$ \\
\hline $\begin{array}{l}\text { Maternal positive food } \\
\text { comments }\end{array}$ & $5.00(8.00)$ & $6.34(5.78)$ & $0.00 / 25.00$ \\
\hline $\begin{array}{l}\text { Proportion of } \\
\text { familiar/appealing } \\
\text { foods consumed }\end{array}$ & $0.71(0.71)$ & $0.65(0.35)$ & $0.03 / 1.00$ \\
\hline $\begin{array}{l}\text { Proportion of } \\
\text { familiar/unappealing } \\
\text { foods consumed }\end{array}$ & $0.07(0.15)$ & $0.14(0.18)$ & $0.00 / 0.88$ \\
\hline $\begin{array}{l}\text { Proportion of } \\
\text { unfamiliar/appealing } \\
\text { foods consumed }\end{array}$ & $0.31(0.48)$ & $0.39(0.33)$ & $0.00 / 1.00$ \\
\hline $\begin{array}{l}\text { Proportion of } \\
\text { unfamiliar/unappealing } \\
\text { foods consumed }\end{array}$ & $0.05(0.48)$ & $0.18(0.28)$ & $0.00 / 1.00$ \\
\hline Meal duration & $19.00(6.00)$ & $19.00(4.90)$ & $9.00 / 29.00$ \\
\hline
\end{tabular}


751 Note. IQR = interquartile range, $\mathrm{SD}=$ standard deviation

752

753 Table 5: Two-tailed Pearson's partial correlations and bootstrapped 95\% confidence intervals

754 for relationships between maternal reports of food fussiness and observed mealtime

755 behaviours

\begin{tabular}{llll}
\hline Observed mealtime & r & p & CI $^{\text {95\% }}$ \\
behaviour & & &
\end{tabular}

\begin{tabular}{lccc}
\hline Food refusal & .49 & $<.001$ & {$[.27, .67]$} \\
\hline Spitting food & .44 & $<.001$ & {$[.22, .61]$} \\
& & & \\
\hline Playing with food & .46 & $<.001$ & {$[.23, .62]$}
\end{tabular}

Licking food

.36

.003

$[.09, .56]$

Touching food

.47

$<.001$

$[.28, .63]$

Smelling food followed by

.22

.057

$[-.03, .41]$

rejection

Child negative food

.46

$<.001$

$[.24, .62]$

comments

Food consumption

$-.24$

.046

$[-.45,-.01]$

Child positive food

$-.35$

.004

$[-55,-.13]$

comments

Proportion

$-.39$

.001

$[-.59,-.17]$

familiar/appealing food

consumed 


\begin{tabular}{llll}
\hline Proportion & -.10 & .418 & {$[-.34, .09]$}
\end{tabular}

familiar/unappealing food

consumed

$\begin{array}{llll}\text { Proportion } & -.09 & .479 & {[-.30, .15]}\end{array}$

unfamiliar/appealing food

consumed

\begin{tabular}{llll}
\hline Proportion & -.06 & .642 & {$[-.29, .19]$}
\end{tabular}

unfamiliar/unappealing food

consumed

756

757

758

759

760

761

762

763

764

765

766

767

768

769

770

771

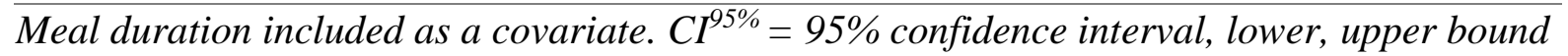
values.

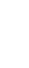

(1)

\section{1}

62


Table 6: Two-tailed Pearson correlations and bootstrapped 95\% confidence intervals for relationships between meal duration, maternal reports of food fussiness and observed mealtime behaviours.

\begin{tabular}{|c|c|c|c|}
\hline & $\mathrm{r}$ & $\mathrm{p}$ & $\mathrm{CI}^{95 \%}$ \\
\hline Food Fussiness & -.03 & .795 & {$[-.28, .21]$} \\
\hline Spitting food & -.02 & .868 & {$[-.32, .24]$} \\
\hline Playing with food & -.04 & .739 & {$[-.30, .20]$} \\
\hline Licking food & -.13 & .309 & {$[-.37, .15]$} \\
\hline Touching food & -.11 & .386 & {$[-.37, .18]$} \\
\hline $\begin{array}{l}\text { Smelling food followed } \\
\text { by rejection }\end{array}$ & -.14 & .268 & {$[-.36, .11]$} \\
\hline Food consumption & .30 & .013 & {$[.07, .52]$} \\
\hline Food refusal & -.07 & .585 & {$[-.31, .19]$} \\
\hline $\begin{array}{l}\text { Child negative food } \\
\text { comments }\end{array}$ & -.91 & .440 & {$[-.36, .19]$} \\
\hline $\begin{array}{l}\text { Child positive food } \\
\text { comments }\end{array}$ & -.13 & .285 & {$[-.11, .38]$} \\
\hline $\begin{array}{l}\text { Maternal negative food } \\
\text { comments }\end{array}$ & -.11 & .384 & {$[-.01, .27]$} \\
\hline $\begin{array}{l}\text { Maternal positive food } \\
\text { comments }\end{array}$ & -.03 & .827 & {$[-.24, .29]$} \\
\hline
\end{tabular}


779 Supplementary Material

780 Table 1: Bootstrapped Pearson's correlations between child age, maternal age with food

781 fussiness and observed mealtime behaviours

\section{Child age}

Maternal age

\begin{tabular}{lcc}
\hline Food Fussiness & .15 & -.23 \\
\hline Smelling food followed by rejection & -.206 & -.04 \\
\hline Touching food & .20 & .07 \\
\hline Licking food & .02 & .12 \\
\hline Playing with food & .11 & -.01 \\
\hline Food refusal & .16 & -.07 \\
\hline Food consumption & .17 & .13 \\
\hline Spitting food & -.02 & -.08 \\
\hline Child negative food comments & .05 & -.09 \\
\hline Child positive food comments & & \\
\hline Maternal negative food comments & -.06 & -.03 \\
\hline Maternal positive food comments & .06 & .01 \\
\hline Meal duration & & -.13 \\
\hline & & \\
\hline & & \\
\hline
\end{tabular}


Table 2: Bootstrapped Independent Samples t-tests comparing means of child sex, maternal ethnicity, maternal education, marital status with food fussiness and observed mealtime behaviours.

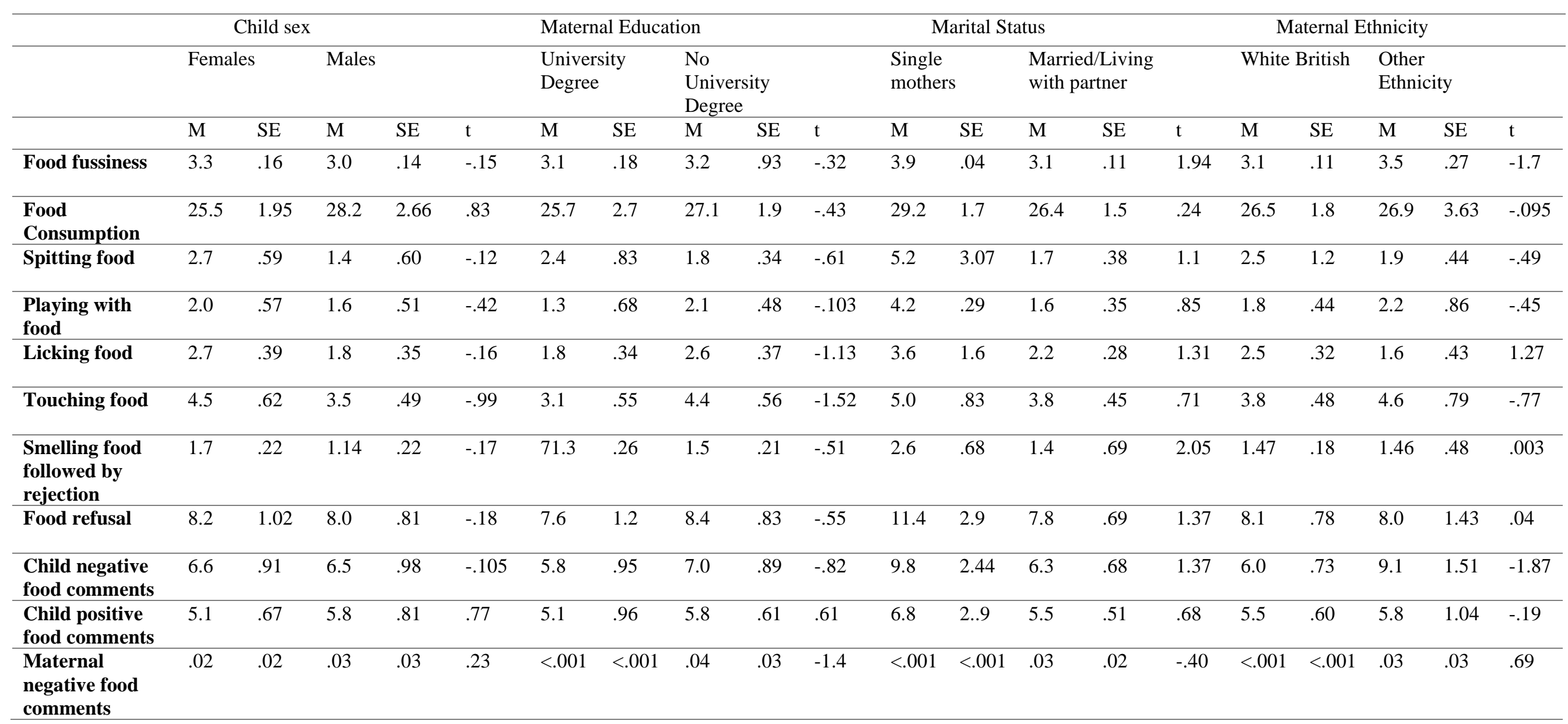


Validation of the CEBQ FF 41

\begin{tabular}{|c|c|c|c|c|c|c|c|c|c|c|c|c|c|c|c|c|c|c|c|c|}
\hline $\begin{array}{l}\text { Maternal } \\
\text { positive food } \\
\text { comments }\end{array}$ & 6.1 & .87 & 6.7 & 1.2 & .39 & 7.2 & .94 & 4.7 & .93 & -1.9 & 10.2 & 3.12 & 6.03 & .71 & 1.6 & 6.35 & .82 & 6.31 & 1.36 & .02 \\
\hline Meal duration & 19.3 & .89 & 18.7 & .68 & -.53 & 19.0 & .70 & 18.9 & 1.11 & -.13 & 18.6 & .75 & 19.0 & .64 & -.47 & 18.7 & .67 & 20.5 & 1.18 & -.13 \\
\hline
\end{tabular}

There were no significant differences between groups across all analyses. $\mathrm{M}=$ mean, $\mathrm{SE}=$ standard error mean. 
791

792

793

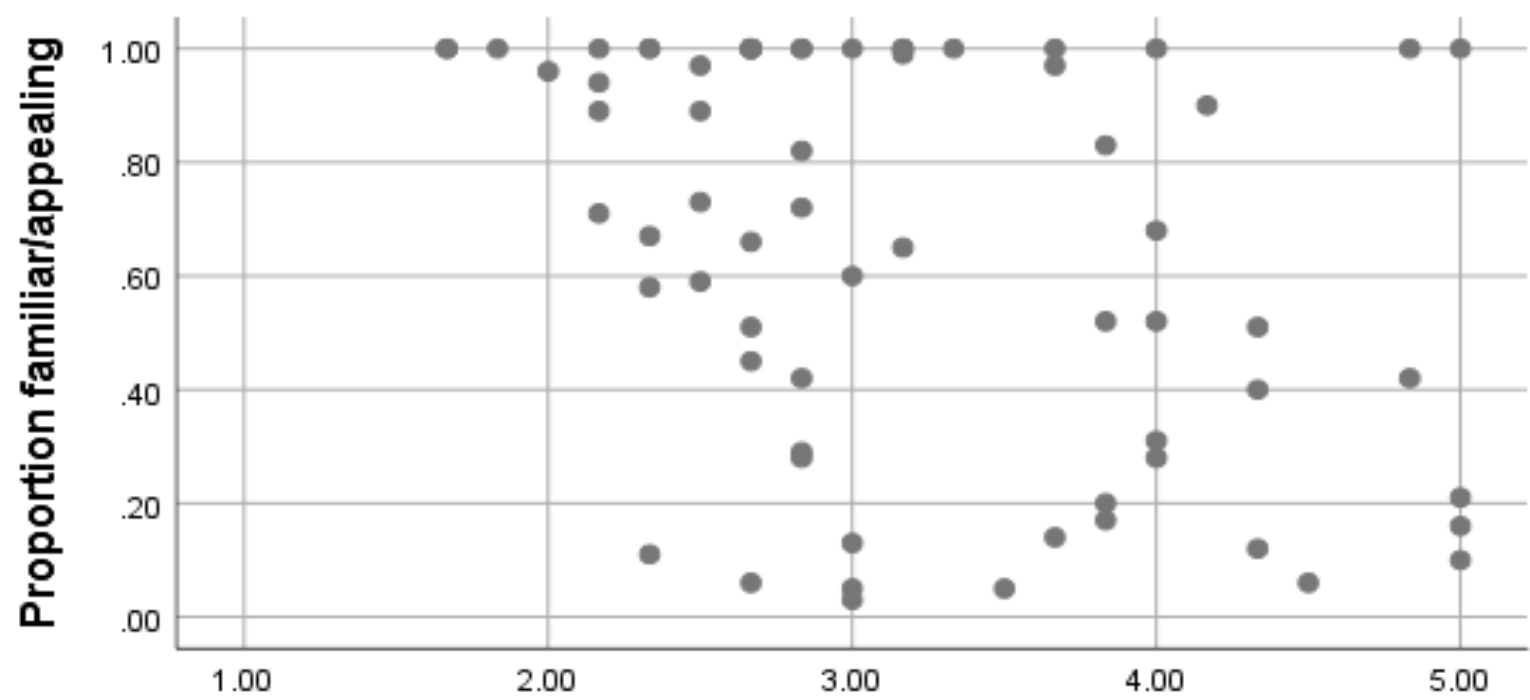

Food fussiness score

Figure 1: Scatterplots depicting association between food fussiness and proportion of foods consumed

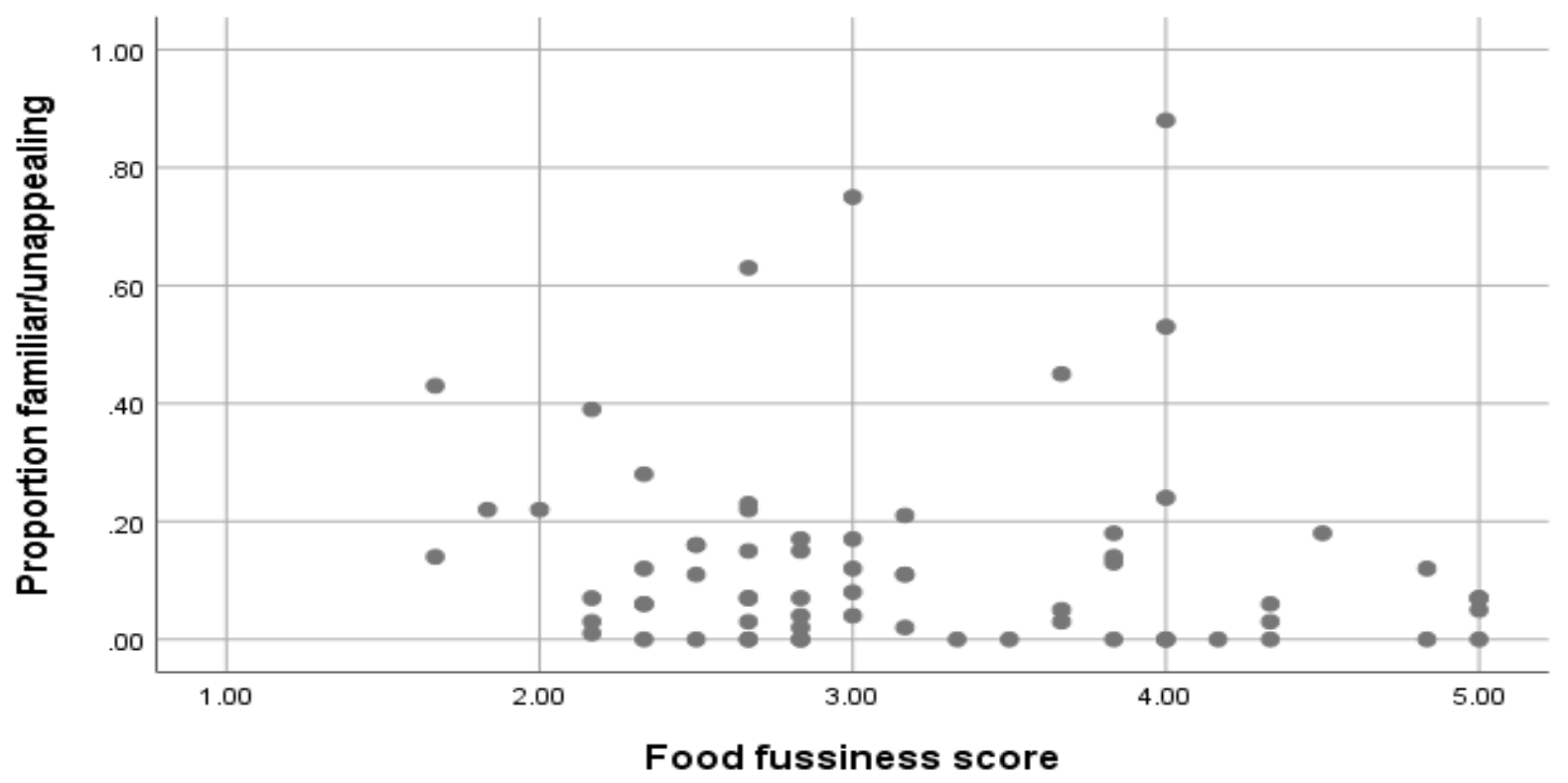




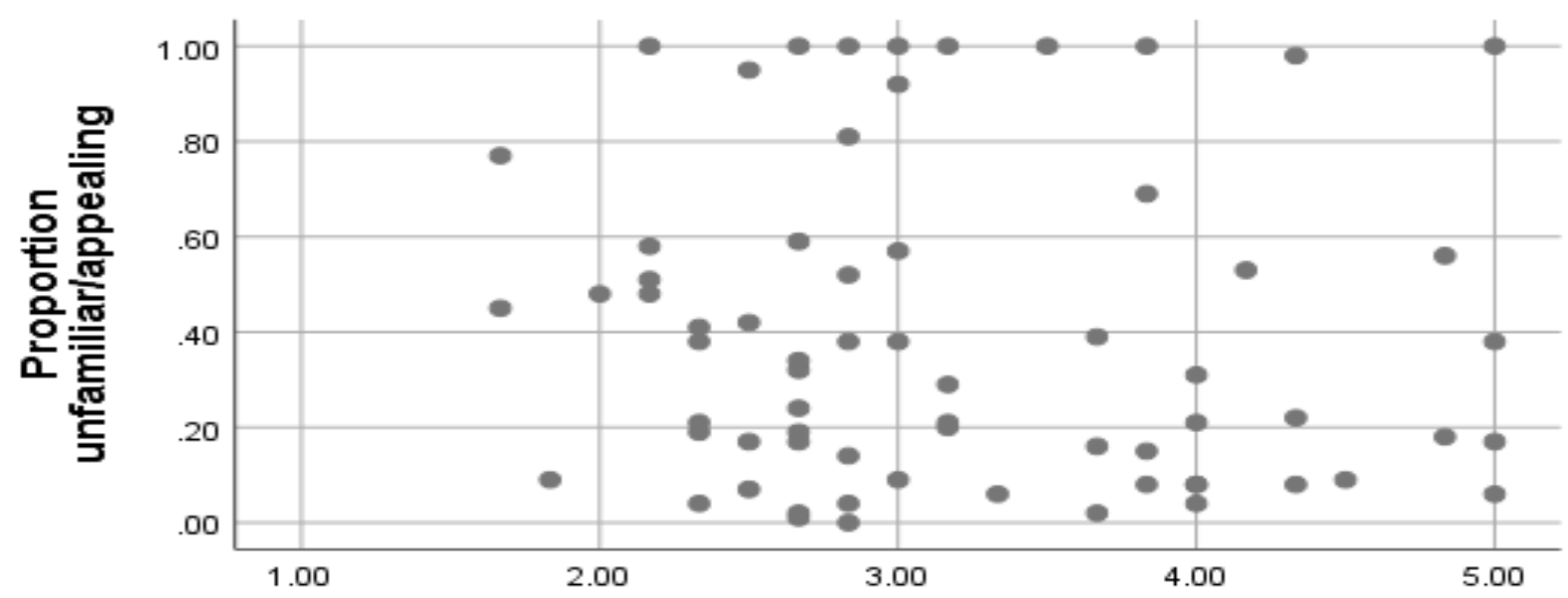

Food fussiness score

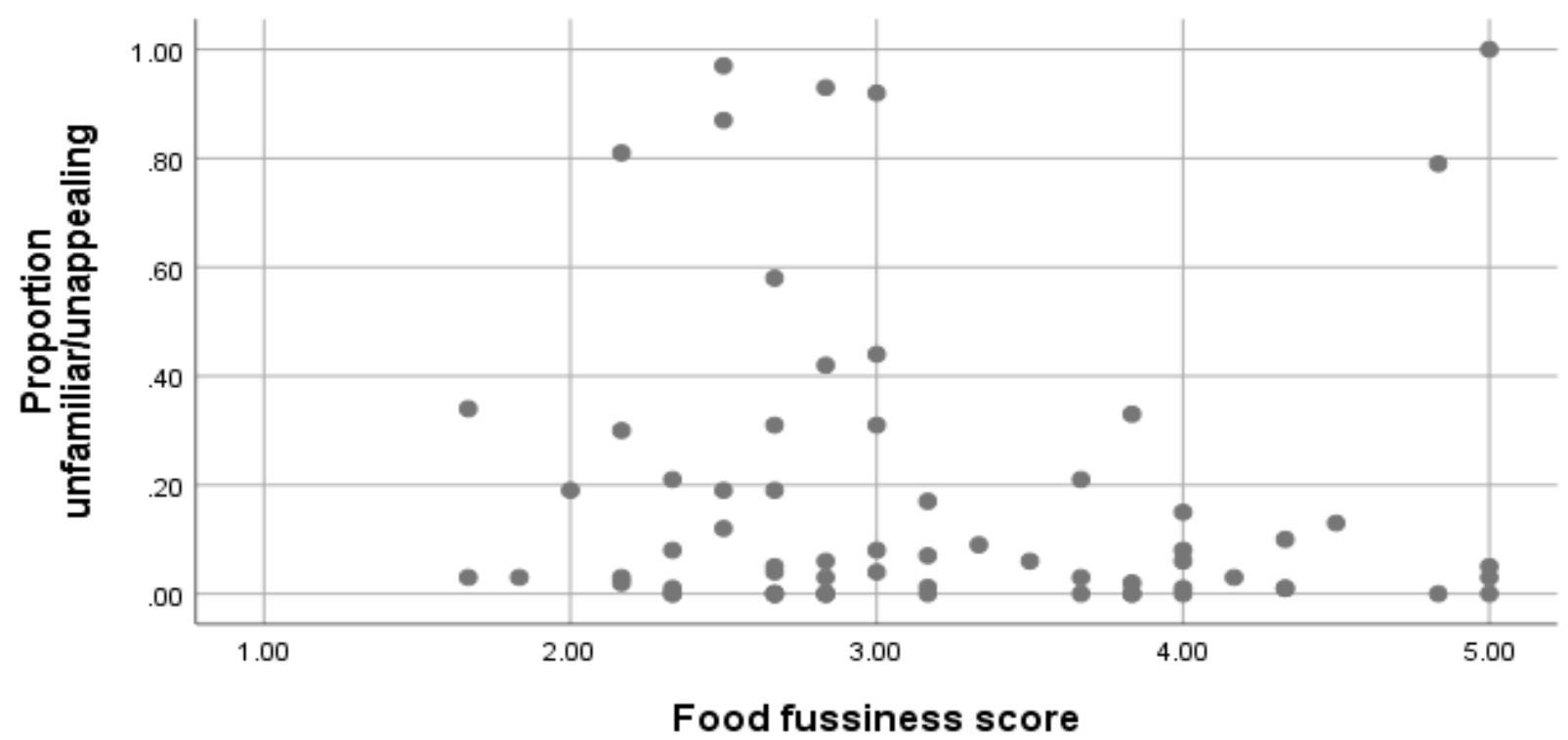

803 